the frozen pipe at about $150 \mathrm{amp}$. It is found that the normal $\frac{1}{2}$-in. lead service pipe thaws out in five to seven minutes. Mr. Salt says that in cases of sickness where there is no water supply and consequently no kitchen fire or other means of providing hot water, this remedy has been much appreciated.

\section{New Physical Apparatus}

Prof. C. J. Overbeck of Evanston University, Illinois, directs attention to some of the recent improvements in apparatus for physical research developed in the United States during the last four years, in a twelve-page illustrated article in the January issue of the Journal of Scientific Instruments. He deals with fractionating oil-diffusion pumps of both glass and metal and with the use of sylphon (metal bellows) for producing adjustments in evacuated spaces from outside without interfering with the vacuum. He describes a centrifuge suspended and run in a vacuum, a new apparatus for determining $e / m$ for electrons, and a device for renewing the emitting surface of an oxide cathode. The Bureau of Standards apparatus for attaching to free balloons which signals its records and weighs only $5 \mathrm{lb}$. is also mentioned. Some examples of the use of Polaroid for stress analysis are given, and a vacuum grating spectrograph for investigating infra-red rotation spectra is described. The advantages of the new synthetic lithium fluoride crystals combined with quartz in a lens doublet, achromatic over a wide range of wave-lengths, are illustrated by spectrograms. References to thirty-one sources of further information are given, and Strong's "Procedures in Experimental Physics" (New York, 1938) is mentioned as of great value for its up-to-date laboratory devices.

\section{Seedlings in Transit : a New Method}

ScIEnce Service, of Washington, D.C., reports the extensive use of a new and simple method of protecting young seedlings of tomato and cabbage from drying out during transit, which may have considerable importance in Great Britain at the present time. Dr. R. N. Du Puis of Chicago suggested that the plants might survive better if the sphagnum in which the roots were wrapped were moistened with a glycerine solution instead of with water. After encouraging large-scale experiments in 1939, the method was brought into commercial use, more than 75 million seedlings being shipped from the south to the north under these conditions. The new mothod apparently saved much loss from drying out and is also stated to give protection against fungus troubles.

\section{The National Book Council}

IT was a wise statesman who said that we must educate our masters, the democracy of to-day, and the National Book Council's latest report, 1938-39, is full of a well-backed forward movement with a new Consultative Committee designed to promote more book-reading. At present, the public libraries are used by about 15 per cent of the population, which remain in ignorance of the chances they have to improve their knowledge, or at least get sound information about their hobbies and the special line of reading they prefer. "Four to Fourteen" for young people has already become a standard bibliography, and "Summer Holiday Reading", a select list of new books, has led to demands beyond the large number printed. Such guides through the present overgrown jungle of books are essential to-day.

The 38-page "Catalogue of Books for the Services" is a good and wisely catholic selection, due to the Council and the Society of Authors acting together. It gives learned and popular theology on one page and on another a choice of thrillers by Dorothy Sayers, science, plays, essays, and fiction, old as well as new. We notice one omission in the judicious section of poetry; Kipling's two early books of soldier jingles are included, but where is the "Collected Verse" of his more mature years ? That volume holds many well-known pieces and celebrates the work of our Navy with the "Wet Litany", "Mine Sweepers", "The North Sea Patrol" and other vivid things not easily forgotten. Evacuees, both young and adult, have raised new problems of booksupply, in towns and villages unequal to the demand, and the Council has suggested to the Board of Education sound plans to arouse interest and supply the books needed.

\section{Earthquakes in Greece}

STrong earthquakes were experienced last week in the town of Ekaterini at the foot of Mount Olympus on the shores of the Gulf of Salonica in Greece. On the morning of February 1, several tremors and one or two earthquakes occurred to the accompaniment of loud and long-continued underground rumbling. Some houses collapsed. On February 2 the shocks continued, there being eighteen in all. About 120 buildings, including some schools, the law courts and the post office, collapsed or became severely damaged. The casualty numbers have not yet been published. Tents have been erected as temporary dwellings and the postal headquarters are reported to be temporarily in a tent. Medical supplies and anti-typhoid vaccines have been sent from Salonica. It will be remembered that a severe earthquake wrecked several villages in the Chalcidice district of Greece on the night of September 27-28, 1932. The epicentre was then estimated to have been between Salonica and Mount Athos (Nature, October 8, 1932 , p. 537), which is to the north-east of the present epicentres.

\section{Earth Tremors in Scotland}

SLIGHT earth tremors are reported to have occurred on February 3 at Stirling in Scotland. No damage has been done. The tremors may have been occasioned by slipping along a local fault. Similar tremors were reported from Roslin, near Edinburgh, on February 10, 1934, though the most active region seismically in Scotland is near Comrie in Perthshire, where the slight tremors are considered to be due to slipping along the Highland Boundary Fault system. 